\title{
NUCLEUS SEED MULTIPLICATION
}

\author{
E. Kevern
}

The multiplication of Nucleus Seed to produce Breeders' Seed of any of the Grasslands Division cultivars not covered by Head Licensees is handled by the Grasslands Division Seed Production Specialist. The procedure for the selection of increase areas is as follows.

The Region: Wherever possible, cultivars are kept to districts that produce that type of cultivar already. As an example, 'Grasslands Ruanui' perennial ryegrass is grown at Waitohi in South Canterbury. This helps eliminate chance of crosspollination, provides better isolation, and reduces the likelihood of disagreements between neighbouring farmers. Moata is grown at Russells Flat, and Manawa at Opihi.

Locality, soil type and paddock area must be considered next. Requirements vary according to cultivar.

Cropping History: The chosen paddock must have had a sufficient time interval between crops of different species, or different cultivars of the same species, to meet certification standards. The Ministry of Agriculture and Fisheries' (MAF) Seed Certification booklet states the requirements clearly.

Isolation: Isolation must meet MAF's requirements. If it is planned to grow a seed crop on a boundary, discussion with the neighbour must take place to ensure that the adjacent paddocks do not cause rejection of part or all of the areas.

Weeds: There should be no undesirable weeds on the property when growing high grade, genetically pure seed. It is too valuable to be wasted in a paddock that could be rejected from certification due to the presence of nodding thistle, yellow gromwell, or wild mats (depending upon what cultivar is being grown).

Diseases: Farms with a known history of 'farm-borne, diseases such as smut, or blind-seed disease are avoided.

Irrigation: In most cases,: irrigation. should be available. It is not, however, a criterion as some soil types and areas do not generally require it.

Other Cultivars: Care must be taken, not to select a farmer who is growing several other species unless he has access to a 'clean' header. If this is not the case, physical contamination at harvesting is a certainty. 
Equipment: The grower should have, or have access to, a full range of efficient equipment. Contractors can do a good job, but many do not take time to clean down properly between cultivars or properties.

The Farmer: The farmer must be considered. He must be a specialist grower and interested in the crop. A grower who is not interested could ruin the crop with carelessness (e.g., by contaminating it with. dirty equipment such as tractors, drills, truck or trailer decks, or by feeding out hay or straw of another cultivar on the paddock in winter).

In summary, anybody involved in or considering the production of high grade seed is advised to read the section of MAF's current Seed Certification booklet that pertains to each herbage crop being contemplated. They are also advised to consider whether their region is suitable for the cultivar being considered, whether there is a potential weed problem, and whether they have access to suitable equipment, plus cleaning gear for that equipment. Finally, it should be remembered that every time machinery is taken into the paddock it could be a source of contamination unless clean. Roguing takes time and time is money. 